\section{INTERVENTIONS FOR STRENGTHENING CAPACITIES OF HIGHER EDUCATION INSTITUTIONS IN DEVELOPING COUNTRIES - REFLECTIONS FROM THE FIELD}

Sumit S Kane, Swe Swe Aye. KIT Royal Tropical Institute, Amsterdam, The Netherlands

\subsection{6/bmjopen-2015-forum2015abstracts.60}

Background Literature shows that the institutional capacity building literature tends to have a narrow focus on those whose capacities are being built, and an overly technical focus on the "capacities" that need to be built. The literature is largely silent on "how" the "technical experts" should approach the process of building capacity.

Objectives We present our reflections from a 3 year project on strengthening the capacity of a higher education institution in India. The aim was to gain insight about the question "What is it about the "conduct" of someone who claims expertise and claims the ability to build someone else's capacity, that, either leads to successful building of capacity, or, as we all know, resistance and rejection of the support being offered".

Methods "Critical self-reflection" is used as a research method. According to Fook et al (2011), this method can help illuminate the way we engage with our work in complex, integrated and fluid ways; it can then yield new and valuable insights about our professional practice. Thirteen members of the ITS project team were approached for the study; 12 agreed to participate; 1 refused on the grounds that he did not agree with the scope of the assessment; 1 agreed but did not finish the process. Participants initially responded to a brief semi-structured questionnaire, via email. After a week's time gap, an interview was conducted by Skype to further reflect on the responses given in the initial questionnaire. These pieces (the questionnaire and the interview) were recorded and transcribed verbatim; transcripts were analysed using NVivo to arrive at emerging themes that provided insight about the questions of interest.

Result Capacity building is a complex and challenging endeavor. Capacity building practitioners need to be able to navigate a complex web of individual, institutional and relational domains in short periods of time to achieve desired change. Capacity building initiatives - organizations and practitioners, to be able to make difference, need to fully understand the individual, institutional and relational domains of the context in which they intend to act; they also must constantly reflect upon their own approach, actions and conduct - both as organizations and individual practitioners. Building trust between the capacity builders and those whose capacities are being built, is key; and trust can only be earned through an approach based on humility, openness and patience.

Conclusion We found that capacity building programs and practitioners should steer clear of "hubris'; that the most important attributes of those who claim "technical expertise" and seek to build others' capacities, are "humility", “openness', and "patience". These are essential elements in developing each other's trust. Reflections of the team suggest that this is particularly so for capacity building interventions targeted at higher education institutions. These elements are either missing, or barely touched upon in the theoretical literature on institutional capacity building - this empirical work adds to the theory by making these elements explicit.

\section{REFERENCE}

1 Fook Jan. Developing critical reflection as a research method. In: Higgs J, et al., (eds.), Creative Spaces for Qualitative Researching: Living Research. Sense Publishers. Rotterdam, 2011;55-64. 